\title{
99m Tc-Labeled Small-Molecule Inhibitors of Prostate-Specific Membrane Antigen for Molecular Imaging of Prostate Cancer
}

\author{
Shawn M. Hillier, Kevin P. Maresca, Genliang Lu, Ross D. Merkin, John C. Marquis, Craig N. Zimmerman, \\ William C. Eckelman, John L. Joyal, and John W. Babich \\ Molecular Insight Pharmaceuticals, Cambridge, Massachusetts
}

Prostate-specific membrane antigen (PSMA) is highly expressed in prostate cancer, and small-molecule radiopharmaceuticals targeting PSMA rapidly detect the location and extent of disease. Here we evaluated preclinically 4 novel $99 \mathrm{mTc}$-labeled small-molecule inhibitors of PSMA with the potential for clinical translation for molecular imaging of prostate cancer in humans. Methods: Four PSMA inhibitors derived from the glutamate-urea-glutamate or glutamate-urea-lysine pharmacophores conjugated to CIM or TIM chelators were radiolabeled with ${ }^{99 \mathrm{~m} T c}$ and evaluated in vitro and in vivo. Results: High-affinity, saturable binding to PSMA on LNCaP cells was observed with $K_{\mathrm{d}}$ values of $0.64 \pm 0.46 \mathrm{nM}$ for ${ }^{99 \mathrm{mTc}} \mathrm{Tc}$ MIP-1427, $1.07 \pm 0.89 \mathrm{nM}$ for $99 \mathrm{mTc}-M I P-1404,1.75 \pm 0.32 \mathrm{nM}$

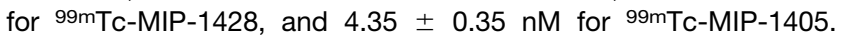
99mTc-labeled PSMA inhibitors did not bind human prostate cancer PC3 cells, which lack PSMA, demonstrating specificity, and binding was abolished with 2-(phosphonomethyl)pentanedioic acid (PMPA), a structurally unrelated PSMA inhibitor. ${ }^{99 m}$ Tc-labeled PSMA inhibitors were shown to internalize at $37^{\circ} \mathrm{C}$. Uptake in $\mathrm{LNCaP}$ xenografts ranged from $9.3 \%$ to $12.4 \%$ injected dose per gram at $1 \mathrm{~h}$ after injection and from $7.2 \%$ to $11.0 \%$ at $4 \mathrm{~h}$, with tumor-to-blood ratios ranging from 29:1 to $550: 1$ and tumor-toskeletal muscle ratios ranging from $31: 1$ to $157: 1$ at $4 \mathrm{~h}$. ${ }^{99 m T c}$ MIP-1404 exhibited the best combination of high tumor uptake and rapid clearance from kidney and nontarget tissues. ${ }^{99 m T c-}$ MIP-1404 specifically bound to PSMA in vivo as demonstrated by the absence of uptake in $\mathrm{PC} 3$ xenografts and by competition with PMPA. SPECT/CT imaging corroborated the tissue distribution results, demonstrating uptake only in PSMA-expressing kidney and tumor tissue and clearance through the urinary bladder. Conclusion: These ${ }^{99 m T c-l a b e l e d ~ r a d i o p h a r m a c e u t i c a l s ~ t a r g e t i n g ~}$ PSMA may provide a SPECT molecular imaging option to assist in the initial diagnosis of prostate cancer and the management of patient care by monitoring disease progression.

Key Words: prostate cancer; PSMA; imaging; SPECT

J Nucl Med 2013; 54:1369-1376

DOI: 10.2967/jnumed.112.116624

$\mathbf{M}$

anagement of prostate cancer is challenging because of the many clinical factors and treatment options to be considered in

Received Oct. 31, 2012; revision accepted Feb. 11, 2013

For correspondence or reprints contact: John W. Babich, Molecular Insight Pharmaceuticals, 160 Second St., Cambridge, MA 02142.

E-mail: jbabich@molecularinsight.com

Published online Jun. 3, 2013.

COPYRIGHT (C 2013 by the Society of Nuclear Medicine and Molecular Imaging, Inc. deciding on the optimal therapy for a given patient. Because early detection is allowing men to live much longer with the disease, clinical decision making may have long-term consequences. Accurately defining the extent and location of disease burden and the aggressiveness of the disease at initial diagnosis are important factors in treatment selection. Hence, the ability to visualize disease throughout the body is increasingly important for informing therapeutic selection and treatment planning. Current imaging techniques including MR imaging, CT, and bone scanning offer some opportunity to visualize disease in various parts of the body, but none provides both highly specific and highly sensitive detection of metastatic prostate cancer (1-3). New imaging agents that provide a sensitive and specific means of imaging tumor burden throughout the body, in both soft tissue and bone, to more accurately detect and stage disease and monitor response to therapy will improve disease management, patient outcomes, and quality of life.

Prostate-specific membrane antigen (PSMA), an attractive molecular target for the detection of primary and metastatic prostate cancer, is expressed primarily in normal human prostate epithelium and is upregulated in prostate cancer, including metastatic disease (4-6). Reports indicate that overexpression of PSMA in primary prostate cancer correlates with other adverse traditional prognostic factors and independently predicts disease outcome $(7,8)$. Because PSMA is expressed by virtually all prostate cancers and its expression is further increased in poorly differentiated, metastatic, and hormone-refractory carcinomas (5), it is an attractive target for developing radiopharmaceuticals for the diagnosis, staging, and treatment of the disease.

PSMA is highly homologous to $N$-acetylated $\alpha$-linked acidic dipeptidase (NAALADase), a neuropeptidase that produces the neurotransmitter glutamate and $\mathrm{N}$-acetylaspartate through hydrolysis of $\mathrm{N}$-acetylaspartylglutamate $(9,10)$. Analysis of the crystal structure of PSMA has aided in understanding of the critical interactions of potent inhibitors within the active site of the enzyme and has led to the design and synthesis of several classes of NAALADase inhibitors that are substrate or transition state analogs $(11,12)$.

We recently synthesized and evaluated a series of PSMA inhibitors, which resulted in the identification of several lead iodine-containing molecules that may be applicable for radioimaging and radiotherapy of prostate cancer (13). These radioiodinated glutamate-urea heterodimers demonstrated high affinity for PSMA and the ability to detect prostate tumors in mice (14), thereby establishing their potential for imaging prostate cancer in humans. Lead compounds have entered clinical development for monitoring disease recurrence after biochemical failure in prostate cancer patients and in early clinical trials have been shown to detect metastatic prostate tumors in bone and lymph nodes (15). 
${ }^{99 \mathrm{~m}} \mathrm{Tc}$ has become the mainstay of diagnostic nuclear medicine using SPECT and in some chemical form is used in more than $85 \%$ of the diagnostic scans performed each year in hospitals. The preferential use of ${ }^{99 \mathrm{~m}} \mathrm{Tc}$ radiopharmaceuticals reflects the ideal nuclear properties of the radionuclide, as well as its convenient availability from commercial generators. ${ }^{99 \mathrm{~m}} \mathrm{Tc}$ emits a $140-\mathrm{keV}$ $\gamma$-ray with $89 \%$ abundance, which is optimal for imaging with commercial $\gamma$-cameras. The lack of $\beta$-particles and particulate radiation allows the injection of activities of more than 1.11 $\mathrm{GBq}(30 \mathrm{mCi})$ with low radiation exposure to the patient. The 6-h half-life is sufficiently long for pharmaceutical preparation and in vivo accumulation in the target, yet short enough to minimize radiation exposure to the patient and environmental repercussions. In addition, the advent of technetium tricarbonyl chemistry (16) allowed for the possibility of an in situ kitformulated product with potential clinical translation (17).

99mTc-labeled PSMA inhibitors have been previously reported (18-20). However, it is challenging to avoid high liver uptake and slow gastrointestinal clearance, which will confound their use for prostate cancer imaging as most often the cancer metastasizes to the lower spine, pelvis, and lymph nodes within the abdominal cavity. Thus, the development of ${ }^{99 m}$ Tc-labeled PSMA inhibitors that are not rapidly excreted into the intestines is a priority.

We recently designed, synthesized, and evaluated a series of novel second-generation single-amino-acid chelators (SAACs) containing functionalized polar imidazole rings to reduce lipophilicity which, either alone or when conjugated to small molecules and peptides, dramatically diminish hepatobiliary uptake and promote renal clearance (21). Here we describe the biologic evaluation of 4 PSMA inhibitors derived from the glutamate-ureaglutamate or glutamate-urea-lysine pharmacophores incorporating our second-generation SAAC chelators CIM (2,2'-(2,2'-(azanediylbis(methylene))bis(1H-imidazole-2,1-diyl))diacetic acid) or TIM (2,2',2" ,2' ' -((2,2'-(2,2'-(azanediylbis(methylene)) bis( $1 H$ imidazole-2,1-diyl))bis(acetyl))bis(azanetriyl))tetraacetic acid) and radiolabeled with ${ }^{99 \mathrm{~m}} \mathrm{Tc}$ via technetium tricarbonyl chemistry (16). We demonstrate that these compounds bind with high affinity to PSMA and have diminished hepatobiliary clearance. These novel molecule-targeted radiopharmaceuticals may be exploited for the diagnosis, staging, prognosis, and-by switching metals to ${ }^{186 / 188} \mathrm{Re}$ - potential treatment of prostate cancer.

\section{MATERIALS AND METHODS}

\section{Synthesis and Radiolabeling of 99mTc PSMA Inhibitors}

The synthesis of MIP-1404 ((7S,12S,16S)-1-(1-(2-(bis(carboxymethyl)amino)-2-oxoethyl)-1 $H$-imidazol-2-yl)-2-((1-(2-(bis(carboxymethyl) amino)-2-oxoethyl)- $1 H$-imidazol-2-yl)methyl)-9,14-dioxo-2,8,13,15tetraazaoctadecane-7,12,16,18-tetracarboxylic acid), MIP-1405 ((7S, $14 S, 18 S)$-7-amino-1-(1-(carboxymethyl)- $1 H$-imidazol-2-yl)-2-((1(carboxymethyl)-1H-imidazol-2-yl)methyl)-8,16-dioxo-2,9,15,17tetraazaicosane-14,18,20-tricarboxylic acid), MIP-1427 ((7S,12S, 16S)-1-(1-(carboxymethyl)-1H-imidazol-2-yl)-2-((1-(carboxymethyl)$1 H$-imidazol-2-yl)methyl)-9,14-dioxo-2,8,13,15-tetraazaoctadecane-7, 12,16,18-tetracarboxylic acid), and MIP-1428 ((7S, 14S, 18S)-7-amino1-(1-(2-(bis(carboxymethyl)amino)-2-oxoethyl)-1 $H$-imidazol-2-yl)2-((1-(2-(bis(carboxymethyl)amino)-2-oxoethyl)-1H-imidazol-2-yl) methyl)-8,16-dioxo-2,9,15,17-tetraazaicosane-14,18,20-tricarboxylic acid) along with the radiolabeling with ${ }^{99 \mathrm{~m}} \mathrm{Tc}$ were described previously (22). The structures of MIP-1405 and MIP-1427, incorporating the CIM chelate, as well as the structures of MIP-1404 and MIP-1428, which incorporate the TIM chelate, are shown in Figure 1.
Briefly, the ${ }^{99 \mathrm{~m}} \mathrm{Tc}(\mathrm{CO})_{3}{ }^{+}$radiolabeling to form the desired ${ }^{99 \mathrm{~m}} \mathrm{Tc}$

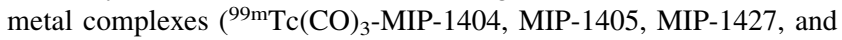
MIP-1428) was accomplished using standard methodology (16) and commercially available IsoLink kits (Covidien) in a volume of $1 \mathrm{~mL}$ to form the $\left[{ }^{99 \mathrm{~m}} \mathrm{Tc}(\mathrm{CO})_{3}\left(\mathrm{H}_{2} \mathrm{O}\right)_{3}\right]^{+}$intermediate, $1.48 \mathrm{GBq}(40 \mathrm{mCi})$, which was subsequently neutralized with $0.2 \mathrm{~mL}$ of $1 \mathrm{~N} \mathrm{HCl}$ and reacted with $0.1 \mathrm{mg}$ of compound (MIP-1404, MIP-1405, MIP1427, and MIP-1428) at a concentration of $10^{-4} \mathrm{M}$ in an equalvolume mixture of acetonitrile and water in a sealed vial. The sealed vial was heated at $100^{\circ} \mathrm{C}$ for $30 \mathrm{~min}$. After cooling and evaporation of the solvent, the tert-butyl ester protecting groups were removed by treatment with $2 \mathrm{~mL}$ of $50 \%$ trifluoroacetic acid in dichloromethane for $45 \mathrm{~min}$ at room temperature. On completion of the deprotection, the reactions were concentrated on a rotary evaporator and purified by high-performance liquid chromatography using a Vydac C18 reversephase column $(250 \mathrm{~mm} \times 4.6 \mathrm{~mm} \times 5 \mu \mathrm{m})$ and a gradient method of $5 \%-50 \%$ buffer $\mathrm{B}$ over 30 min (buffer $\mathrm{A}=$ water $+0.1 \%$ trifluoroacetic acid, buffer $\mathrm{B}=$ acetonitrile $+0.1 \%$ trifluoroacetic acid). The final ${ }^{99 \mathrm{~m}} \mathrm{Tc}$-labeled complexes were dried under a stream of nitrogen and reconstituted in $0.9 \%$ sodium chloride solution ( $\mathrm{pH}$ 5), resulting in no-carrier-added products. The excess chelating agent was separated from the final ${ }^{99 \mathrm{~m}} \mathrm{Tc}$-labeled products to the extent that less than $5 \%$ of the original $10^{-4} \mathrm{M}$ chelate remained). The radiochemical purity was determined via high-performance liquid chromatography using the method above and shown to be consistently at least $95 \%$ pure with $70 \%$ radiochemical yield and specific activity greater than $37 \mathrm{TBq}(1,000 \mathrm{Ci}) / \mathrm{mmol}(22)$.

\section{Cell Culture}

The human prostate cancer cell lines LNCaP (PSMA-positive) and PC3 (PSMA-negative) were obtained from the American Type Culture Collection. Cell culture supplies were from Invitrogen unless otherwise noted. LNCaP cells were maintained in RPMI-1640 medium supplemented with $10 \%$ fetal bovine serum (Hyclone), $4 \mathrm{mM}$ L-glutamine, $1 \mathrm{mM}$ sodium pyruvate, $10 \mathrm{mM}$ HEPES ( $N$-2-hydroxyethylpiperazine- $\mathrm{N}$-2-ethanesulfonic acid), D-glucose $(2.5 \mathrm{mg} / \mathrm{mL})$, and gentamicin $(50 \mu \mathrm{g} / \mathrm{mL})$ in a humidified incubator at $37^{\circ} \mathrm{C} / 5 \% \mathrm{CO}_{2}$. $\mathrm{PC} 3$ cells were

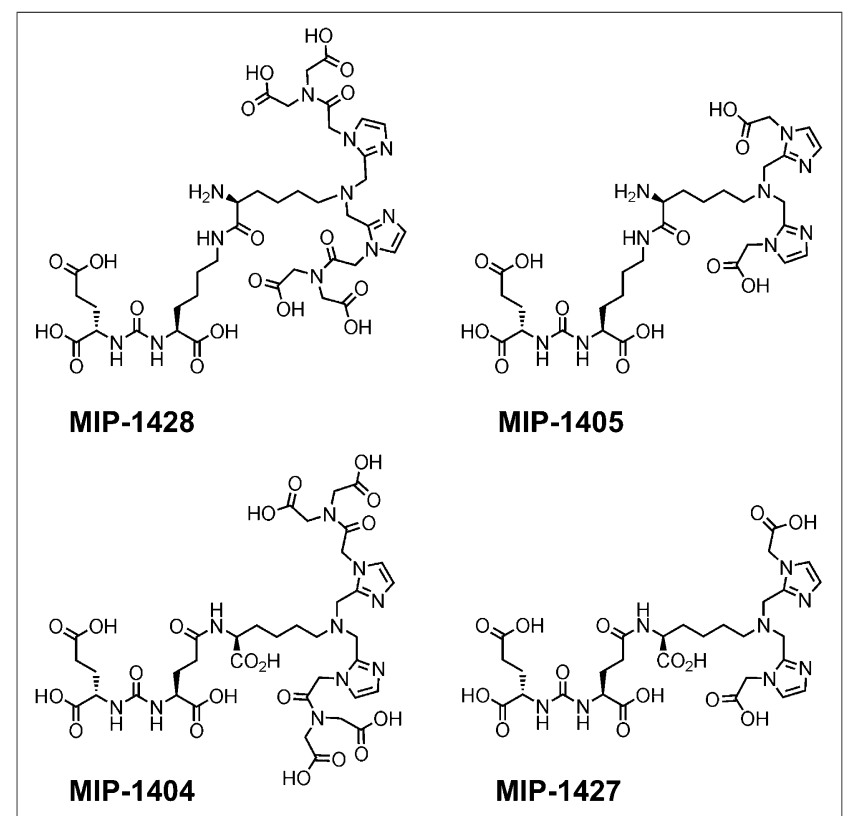

FIGURE 1. Structures of MIP-1404, MIP-1405, MIP-1427, and MIP-1428. 
maintained in F-12K nutrient mixture Kaighn modification medium supplemented with $10 \%$ fetal bovine serum, $2 \mathrm{mM}$ L-glutamine, and gentamicin $(50 \mu \mathrm{g} / \mathrm{mL})$ in a humidified incubator at $37^{\circ} \mathrm{C} / 5 \% \mathrm{CO}_{2}$. Cells were removed from flasks for passage or for transfer to 12-well assay plates by incubating them with $0.25 \%$ trypsin/ethylenediaminetetraacetic acid.

\section{Affinity Measurements}

The affinity constant $\left(K_{\mathrm{d}}\right)$ of ${ }^{99 \mathrm{~m} T c-l a b e l e d ~ P S M A}$ inhibitors was determined by saturation binding analysis. $\mathrm{LNCaP}$ cells $\left(4 \times 10^{5}\right.$ cells per well in 12-well plates in triplicate) were incubated for $1 \mathrm{~h}$ with 0.003-1,000 nM ${ }^{99 \mathrm{~m}}$ Tc-labeled PSMA inhibitors supplemented with the nonradiolabeled rhenium analogs in HEPES buffered saline (50 $\mathrm{mM}$ HEPES, $\mathrm{pH} 7.5,0.9 \%$ sodium chloride) at $4{ }^{\circ} \mathrm{C}$. Nonspecific binding was determined by adding $30 \mu \mathrm{M}$ nonradiolabeled rhenium analogs and subtracted from total binding. The cells were then washed, and the amount of radioactivity was measured on a $\gamma$-counter. Specific binding was calculated as the difference between total binding and nonspecific binding. The $K_{\mathrm{d}}$ was determined by nonlinear regression analysis using GraphPad Prism software.

\section{Binding Specificity}

LNCaP cells and PC 3 cells $\left(4 \times 10^{5}\right.$ cells per well in 12 -well plates in duplicate) were incubated in RPMI-1640 medium supplemented with $0.5 \%$ bovine serum albumin for $1 \mathrm{~h}$ at room temperature with $3 \mathrm{nM}{ }^{99 \mathrm{~m}} \mathrm{Tc}$-labeled PSMA inhibitors or in the presence of $10 \mu \mathrm{M}$ nonradiolabeled rhenium test compound or $10 \mu \mathrm{M}$ 2-(phosphonomethyl)-pentanedioic acid (PMPA) (Axxora), a structurally unrelated NAALADase inhibitor. The cells were washed and counted in an LKB Wallac Model 1282 automated $\gamma$-counter (Perkin Elmer).

\section{Internalization}

LNCaP cells $\left(4 \times 10^{5}\right.$ cells per well in 12 -well plates in duplicates) were incubated in HEPES buffered saline with $100 \mathrm{nM}{ }^{99 m}$ Tc-labeled PSMA inhibitors for $0-2 \mathrm{~h}$ at $4{ }^{\circ} \mathrm{C}$ and $37^{\circ} \mathrm{C}$. At the indicated time, the medium was removed and the cells were washed twice and then incubated with a mild acid buffer $(50 \mathrm{mM}$ glycine, $150 \mathrm{mM} \mathrm{NaCl}, \mathrm{pH}$ 3.0 ) at $4{ }^{\circ} \mathrm{C}$ for $5 \mathrm{~min}$. The cells were then centrifuged at $20,000 \mathrm{~g}$ for 5 min. The supernatant (containing cell surface-bound radioactivity) and the cell pellet (containing internalized radioactivity) were counted on a $\gamma$-counter (23).

\section{Inoculation of Mice with Xenografts}

All animal studies were approved by the Institute for Animal Care and Use Committee in accordance with the guidelines set forth in the Public Health Service Policy on Humane Care and Use of Laboratory Animals (24). The mice were housed under standard conditions in approved facilities with 12-h light/dark cycles and given food and water ad libitum throughout the duration of the studies. Male athymic NCr-nu/nu mice were purchased from Taconic. For inoculation in mice, $\mathrm{LNCaP}$ or PC3 cells were resuspended at $2 \times 10^{7}$ cells $/ \mathrm{mL}$ in a 1:1 mixture of phosphate-buffered saline:Matrigel (BD Biosciences). Each mouse was injected in the right flank with $0.25 \mathrm{~mL}$ of the cell suspension. The mice were used for tissue distribution studies when the tumors reached approximately $100-400 \mathrm{~mm}^{3}$.

\section{Mouse Tissue Distribution}

A quantitative analysis of the tissue distribution of ${ }^{99 \mathrm{~m}} \mathrm{Tc}$-labeled PSMA inhibitors was performed on separate groups of male $\mathrm{NCr}-$ $n u / n u$ mice bearing LNCaP or PC3 cell xenografts administered via the tail vein as a bolus injection of approximately $74 \mathrm{kBq}(2 \mu \mathrm{Ci}) /$ mouse at a specific activity of more than $37 \mathrm{TBq}(1,000 \mathrm{Ci}) / \mathrm{mmol}$ in a constant volume of $0.05 \mathrm{~mL}$. The animals ( $n=5 /$ time point) were euthanized by asphyxiation with carbon dioxide at $0.25,1,2,4,8$, and $24 \mathrm{~h}$ after injection. To examine specificity, other mice $(n=5)$ were coinjected with $10 \mathrm{mg}$ of PMPA per kilogram of body weight and sacrificed at $1 \mathrm{~h}$. Tissues were dissected, excised, weighed wet, and counted in an automated $\gamma$-counter. Tissue time-radioactivity levels expressed as percentage injected dose (\%ID) per gram of tissue were determined. With an average mouse body mass of $25 \mathrm{~g}$ in these studies, and assuming a homogeneous distribution of $99 \mathrm{~m} \mathrm{Tc}, \% \mathrm{ID} / \mathrm{g}$ can be converted to standardized uptake value by dividing $\% \mathrm{ID} / \mathrm{g}$ values by $4(\% \mathrm{ID} / \mathrm{g} / 100 \% / 25 \mathrm{~g})$.

\section{SPECT/CT Imaging}

All in vivo experimental procedures were undertaken in compliance with U.S. laws governing animal experimentation and were approved by the Weill Cornell Medical College of Cornell University institutional animal care and utilization committee. Male BALB/c-nu/nu mice were implanted subcutaneously with $5 \times 10^{6} \mathrm{LNCaP}$ cells. When the tumors reached approximately $5-7 \mathrm{~mm}$ in diameter, the mice were anesthetized using a mixture of ketamine and xylene before radiopharmaceutical injection and during acquisition of the SPECT scan. Mice were injected via the tail vein with $37 \mathrm{MBq}(1 \mathrm{mCi})$ of ${ }^{99 \mathrm{~m}} \mathrm{Tc}-\mathrm{MIP}-$ 1404 at a specific activity of more than $37 \mathrm{TBq}(1,000 \mathrm{Ci}) / \mathrm{mmol}$. Mice bearing LNCaP tumors were imaged for $2 \mathrm{~h}$ after injection. A microSPECT/CT scanner (Inveon; Siemens Medical Solutions, Inc) equipped with 5 low-energy $0.5-\mathrm{mm}$ aperture pinhole collimators and CT was used for all scans. The mice were scanned using 20 bed locations, $9 \%$ step and $10 \mathrm{~s} / \mathrm{view}$ with a total acquisition time of approximately 20 min. A CT scan was obtained before scintigraphy for both anatomic coregistration and attenuation correction. Data were reconstructed and fused using commercial Inveon software from the vendor, which includes a 3-dimensional ordered-subsets expectation maximization algorithm with 8 iterations and 4 subsets per iteration.

\section{RESULTS}

\section{Binding and Internalization}

Saturation binding analysis was conducted to determine the affinity of ${ }^{99 m}$ Tc-MIP-1404, ${ }^{99 m}$ Tc-MIP-1405, ${ }^{99 m}$ Tc-MIP-1427, and ${ }^{99 \mathrm{~m} T c-M I P-1428}$ for PSMA expressed on LNCaP cells. The cells were incubated with $0.003-1,000 \mathrm{nM}{ }^{99 m}$ Tc-PSMA inhibitor to determine the $K_{\mathrm{d}}$ (Fig. 2). Consistent with the order of potency of these compounds in a competitive inhibition assay (22), the affinity for PSMA $\left(K_{\mathrm{d}}\right)$ followed the same rank order: ${ }^{99 \mathrm{~m}} \mathrm{Tc}-$ MIP-1427 $(0.64 \pm 0.46 \mathrm{nM})>{ }^{99 \mathrm{~m}}$ Tc-MIP-1404 (1.07 \pm 0.89 $\mathrm{nM})>99 \mathrm{~m}$ Tc-MIP-1428 (1.75 $\pm 0.32 \mathrm{nM})>99 \mathrm{~m}$ Tc-MIP-1405 $(4.35 \pm 0.35 \mathrm{nM})$.

LNCaP and PC3 cells were incubated with $99 \mathrm{~m}$ Tc-labeled PSMA inhibitors to examine the specificity for PSMA-expressing prostate cancer cells. The compounds bound to the PSMAexpressing LNCaP cells but not to the PSMA-deficient PC3 cells. Furthermore, the binding to LNCaP cells was abrogated with 10 $\mu \mathrm{M}$ nonradiolabeled rhenium analogs or with the structurally unrelated PSMA inhibitor, PMPA. The results using ${ }^{99 \mathrm{~m}}$ Tc-MIP1404 as an example are shown in Figure 3A.

LNCaP cells were also incubated with ${ }^{99 \mathrm{~m}} \mathrm{Tc}$-labeled PSMA inhibitors for up to $2 \mathrm{~h}$ at $4^{\circ} \mathrm{C}$ and $37^{\circ} \mathrm{C}$ to determine whether the compounds are internalized by endocytosis. The cells were then washed with a mild acid buffer to remove extracellularly bound compound. The total binding of ${ }^{99 \mathrm{~m}} \mathrm{Tc}-\mathrm{MIP}-1404$ and the acid-insensitive binding, or internalized compound, to $\mathrm{LNCaP}$ cells is depicted in Figure 3B, as a representative example. The results show a time-dependent increase in radioactivity associated with the cellular pellet at $37^{\circ} \mathrm{C}$ but not at $4^{\circ} \mathrm{C}$, indicating internalization in a temperature-dependent manner. At $4^{\circ} \mathrm{C}$, a temperature at which internalization does not occur, nearly all the radioactivity 


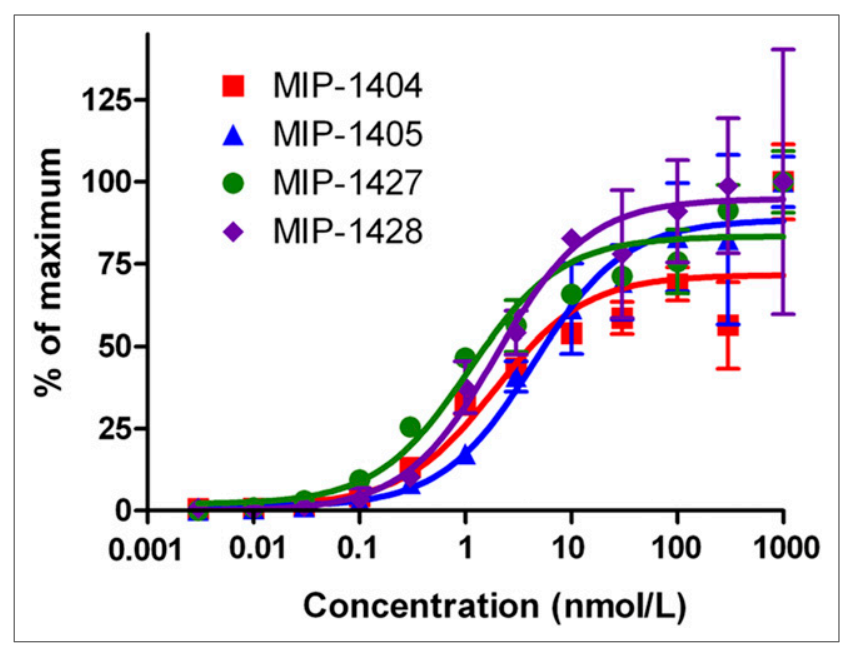

FIGURE 2. Affinity measurements of 99mTc-MIP-1404, 99mTcMIP-1405, 99mTc-MIP-1427, and 99mTc-MIP-1428. LNCaP cells were incubated with 0.003-1,000 nM 99mTc-labeled PSMA inhibitor for $1 \mathrm{~h}$ at $4^{\circ} \mathrm{C} . K_{\mathrm{d}}$ and $\mathrm{B}_{\max }$ were determined by nonlinear regression analysis using GraphPad Prism software.

is removed by the acid wash, indicating that it is surface-bound. Cells incubated for $2 \mathrm{~h}$ at $37^{\circ} \mathrm{C}$ demonstrated internalization of ${ }^{99 \mathrm{~m}}$ Tc-MIP-1404 (699 $\left.\pm 85 \mathrm{fmol}\right),{ }^{99 \mathrm{~m}} \mathrm{Tc}-\mathrm{MIP}-1405(231 \pm 148$ fmol), ${ }^{99 m}$ Tc-MIP-1427 (351 $\left.\pm 61 \mathrm{fmol}\right)$, and ${ }^{99 m}$ Tc-MIP-1428 $(794 \pm 138 \mathrm{fmol})$. These results were confirmed by affinity measurements at $37^{\circ} \mathrm{C}$ showing an elevation in the apparent $\mathrm{B}_{\max }$, further indicating internalization.

\section{Tissue Distribution and Tumor Uptake}

The tissue distribution of ${ }^{99 \mathrm{~m}}$ Tc-labeled PSMA inhibitors was assessed in $\mathrm{NCr}-n u / n u$ mice bearing LNCaP xenografts, and the results are illustrated in Table 1 . The radiolabel was detected at varying levels in all tissues examined and decreased from the 1-h to the 4-h time point in all nontarget tissues. As anticipated, uptake and exposure of the ${ }^{99 \mathrm{~m}} \mathrm{Tc}$-labeled PSMA inhibitors was greatest in the kidney, which expresses high levels of NAALADase (5), and in the PSMA-expressing LNCaP xenograft tumors. Tumor uptake ranged from 9.3 to 12.4 percentage injected dose (\%ID) per gram at the $1-\mathrm{h}$ time point and 7.2-11.0\% ID/g at the 4-h time point, with tumor-to-blood ratios ranging from 29:1 to 550:1 and tumor-to-skeletal muscle ratios ranging from $31: 1$ to $157: 1$ at $4 \mathrm{~h}$. Liver and intestinal uptake was less than $1 \% \mathrm{ID} / \mathrm{g}$ for all compounds at both time points, indicating that these compounds were preferentially excreted via the renal system rather than the hepatobiliary route. Little uptake was detected in the brain, which exhibits high NAALADase activity (25), indicating that the highly charged ${ }^{99 \mathrm{~m}}$ Tc-labeled PSMA inhibitors do not cross the bloodbrain barrier.

99mTc-MIP-1404 exhibited the best tissue distribution profile of the 4 PSMA inhibitors tested: tumor uptake was among the highest at 1 and $4 \mathrm{~h}$, clearance from the kidneys was rapid, liver and intestinal uptake was among the lowest at 1 and $4 \mathrm{~h}$, and the ratios of tumor to blood and tumor to skeletal muscle were the highest at both time points. Therefore, we examined tissue distribution over an extended time course to better examine the pharmacokinetic profile of ${ }^{99 \mathrm{~m}}$ Tc-MIP-1404 (Fig. 4). At 24 h, blood and nontarget tissues were at or below the limit of detection. Kidney uptake peaked at the 15 -min time point $(113 \pm 5 \% \mathrm{ID} / \mathrm{g})$, remained steady through the 2-h time point, and then was more than $90 \%$ cleared by the 4-h time point. Peak LNCaP xenograft tumor uptake was observed at the 2 -h time point $(13.9 \pm 8.5 \% \mathrm{ID} / \mathrm{g})$, but no clearance was observed throughout the duration of the study. There was no statistical difference in tumor uptake at any of the time points examined $(P>0.2)$, likely a result of the high affinity for PSMA. SPECT/CT imaging from 0 to $2 \mathrm{~h}$ was consistent with the tissue distribution results (Fig. 5). Uptake was high in PSMAexpressing kidney and $\mathrm{LNCaP}$ xenograft tissue. Also evident was renal excretion through the bladder.

$\mathrm{NCr}-n u / n u$ mice bearing either $\mathrm{LNCaP}$ or PC3 xenograft tumors were injected with $99 \mathrm{mTc}$-MIP-1404 alone or along with PMPA (10 mg/kg), a structurally unrelated PSMA inhibitor, to demonstrate that binding to $\mathrm{LNCaP}$ tumors was specific to PSMA. ${ }^{99 m}$ Tc-MIP-1404 localized to the PSMA-expressing LNCaP tumor but not to the PSMA-deficient PC3 tumor. Further, binding was abrogated by more than $90 \%$ in the LNCaP tumor and kidney tissue when a $10 \mathrm{mg} / \mathrm{kg}$ dose of PMPA was coinjected, indicating that binding was indeed saturable and specific to PSMA (Fig. 6).

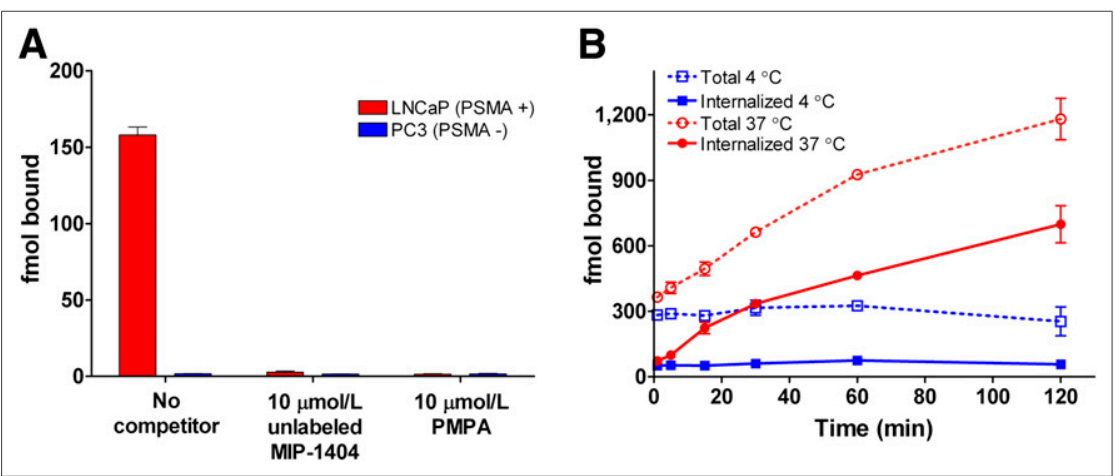

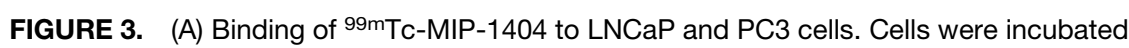
for $1 \mathrm{~h}$ in presence or absence of unlabeled $10 \mu \mathrm{M}$ Re-MIP-1404 or PMPA. (B) Cellular internalization of ${ }^{99 m T C}-M I P-1404$ in $\mathrm{LNCaP}$ cells. $\mathrm{LNCaP}$ cells were incubated at $37^{\circ} \mathrm{C}$ (red lines) or $4^{\circ} \mathrm{C}$ (blue lines) with $100 \mathrm{nM}{ }^{99 \mathrm{mT}} \mathrm{T}-\mathrm{MIP}-1404$ for indicated time, washed, and treated with mild acid buffer to separate total bound material (dashed lines) from internalized (solid lines).

\section{DISCUSSION}

Initial diagnosis, monitoring of disease progression, and evaluation of the recurrence of prostate cancer rely mainly on serum prostate-specific antigen testing. Although the European Randomized Study of Screening for Prostate Cancer showed that initial diagnosis of prostate cancer using PSA screening moderately reduced mortality from prostate cancer (26), the Prostate, Lung, Colorectal, and Ovarian Cancer Screening Trial showed no benefit (27). As a result of these 2 large clinical trials, the U.S. Preventive Services Task Force recently recommended against PSA screening for asymptomatic men, regardless of their age, family history, and ethnicity, because of the harm related to false-positive test results, subsequent evaluation, and therapy, 


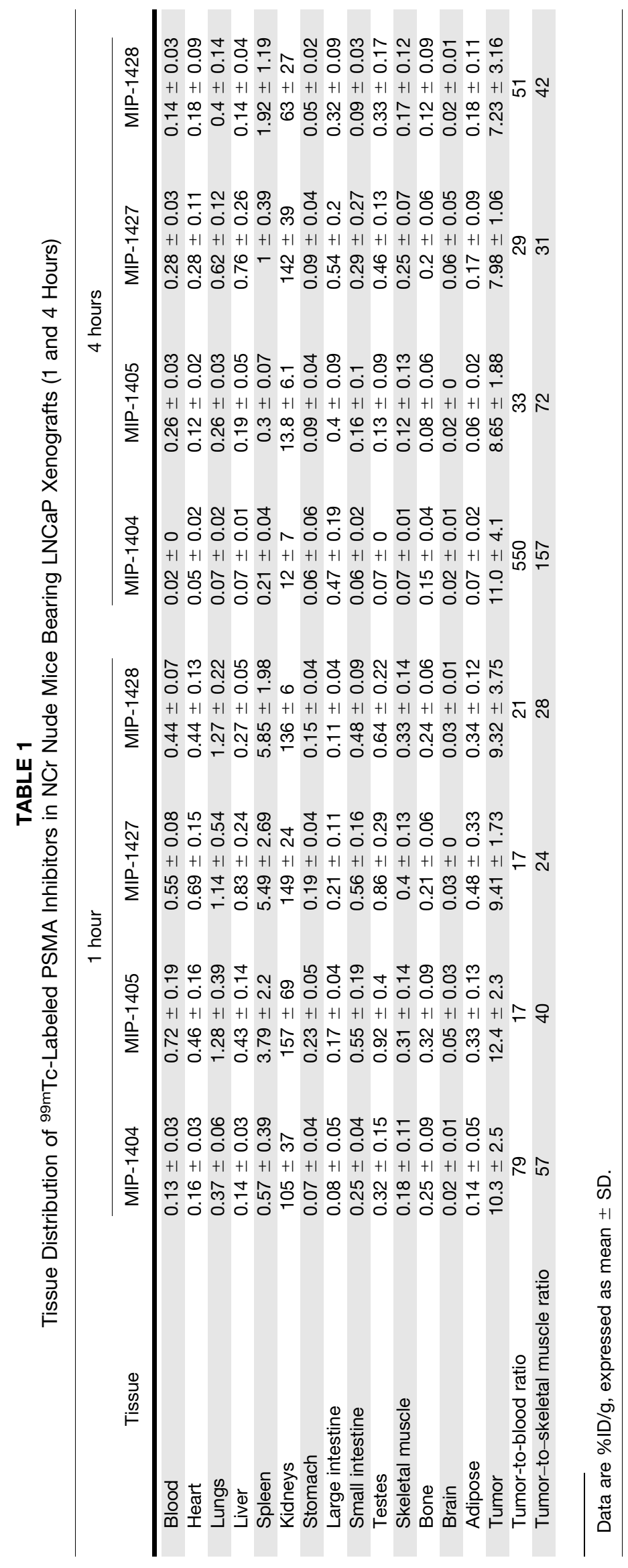




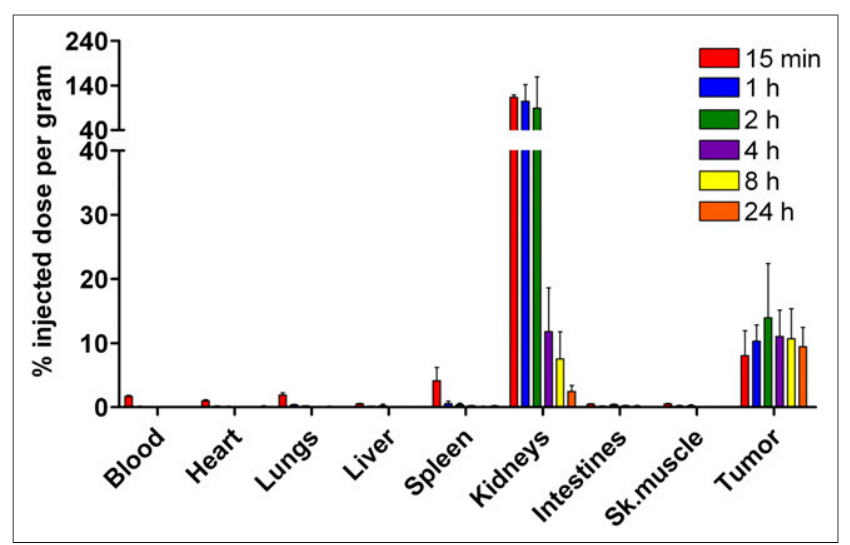

FIGURE 4. Tissue distribution of 99mTc-MIP-1404. 99mTc-MIP1404 was injected into mice bearing LNCaP tumor xenografts, and at indicated time points, tissues were excised, weighed wet, and counted on automated $\gamma$-counter. Data are expressed as \%ID/ g. With average mouse body mass of $25 \mathrm{~g}$ in these studies, and assuming homogeneous distribution of ${ }^{99 \mathrm{mTc}} \% \mathrm{ID} / \mathrm{g}$ can be converted to standardized uptake value by dividing \%ID/g values by 4 (\%ID/g/100\%/25 g). Sk. = skeletal.

including overdiagnosis and overtreatment (28). In addition, since PSA testing is a blood test, it does not inform on disease location and provides little information about the extent of disease.

Molecular imaging with ${ }^{18} \mathrm{~F}-\mathrm{FDG}$ is an efficient means to diagnose and monitor disease progression and recurrence for most solid tumors because of the hypermetabolic rate of cancer cells (29). However, prostate cancer and its metastases generally have a low glycolytic rate, making ${ }^{18} \mathrm{~F}$-FDG imaging essentially ineffective (30). Currently, the only Food and Drug Administrationapproved imaging agent for prostate cancer is the 7E11-C5 monoclonal antibody ${ }^{111} \mathrm{In}$-capromab pendetide, but it is not in widespread use in part because it binds to the intracel-

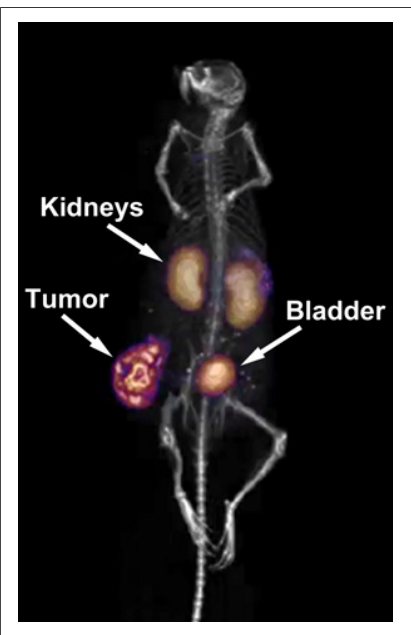

FIGURE 5. Targeting of PSMA in vivo with $99 \mathrm{mTC}-\mathrm{MIP}-1404$. Mice bearing LNCaP tumor xenografts were injected with $37 \mathrm{MBq}$ ( $1 \mathrm{mCi})$ of $99 \mathrm{mTc}-\mathrm{MIP}-1404$ at specific activity of more than 37 $\mathrm{TBq} / \mathrm{mmol}(1,000 \mathrm{Ci} / \mathrm{mmol}))$ and imaged by SPECT/CT at $2 \mathrm{~h}$ with Inveon camera (Siemens).
(35). However, given the widespread availability of ${ }^{99 \mathrm{~m}} \mathrm{Tc}$ and the presence of SPECT cameras in most hospitals throughout the world, the development of a ${ }^{99 \mathrm{~m}} \mathrm{Tc}$-labeled agent targeting a cell surface protein that is upregulated in prostate cancer may be advantageous.

To improve prostate cancer detection for staging disease and to better monitor therapy and disease recurrence, we and others have attempted to image prostate cancer by targeting PSMA using small molecules $(13-15,18-20,36-49)$ and antibodies that target the extracellular domain (41). Our previous work focused on using the glutamate-urea-lysine pharmacophore radiolabeled with an isotope of iodine that exhibited high affinity for PSMA and was found to localize to prostate cancer in animal models and in clinical trials (13-15). The current work uses the same glutamate-urea-lysine pharmacophore as well as a novel glutamate-urea-glutamate pharmacophore to target PSMA, conjugated to either the CIM or TIM second-generation SAAC chelators for ${ }^{99} \mathrm{~m}$ Tc. The affinity measurements demonstrated slightly better PSMA affinity with the glutamate-urea-glutamate-containing compounds, ${ }^{99 \mathrm{~m}} \mathrm{Tc}-\mathrm{MIP}-$ 1404 and ${ }^{99 m}$ Tc-MIP-1427.

The chelators used here are derivatives of lysine that can be incorporated into a variety of small molecules and peptides. They maintain the same robust and stabile coordination of ${ }^{99 \mathrm{~m}} \mathrm{Tc}(\mathrm{CO})_{3}$ as do first-generation SAAC chelates but incorporate carboxylic acid-substituted imidazoles to facilitate rapid renal clearance and diminished hepatobiliary uptake either alone or when conjugated to small molecules (20) and peptides, such as octreotide

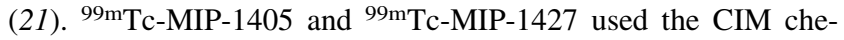
late, whereas the chelate used for ${ }^{99 \mathrm{~m}} \mathrm{Tc}-\mathrm{MIP}-1404$ and ${ }^{99 \mathrm{~m}} \mathrm{Tc}-$ MIP-1428 was further derivatized by adding an extra carboxylic acid group to the CIM chelate and was designated TIM. This additional acid group did not negatively impact the affinity for PSMA. All 4 compounds exhibited high affinity and specificity for PSMA and internalized on binding to PSMA in LNCaP cells, as did previously described small molecules $(14,40)$ and antibodies (10).

The TIM chelate was synthesized with the intention to further decrease nontarget tissue uptake and enhance renal clearance. As is evident in Table 1, this indeed was the case: both ${ }^{99 \mathrm{~m} T c-M I P-}$ 1404 and ${ }^{99 m}$ Tc-MIP-1428 displayed lower uptake and more rapid clearance from the blood, liver, intestines, and most other nontarget tissues than did ${ }^{99 m}$ Tc-MIP-1405 and ${ }^{99 m}$ Tc-MIP-1427, the compounds containing the CIM chelate. Furthermore, the TIM chelate did not diminish uptake or retention in the LNCaP xenograft tumor, as there was no statistical difference between the tumor uptake of any of the compounds at either the 1-h or the 4-h time points.

Of the 4 compounds examined, ${ }^{99 m}$ Tc-MIP-1404 displayed the fastest clearance from kidney and nontarget tissue while retaining binding to the LNCaP tumor over $4 \mathrm{~h} .{ }^{99 \mathrm{~m}} \mathrm{Tc}-\mathrm{MIP}-1404$ also displayed the highest tumor-to-blood and tumor-to-skeletal muscle ratios at both time points. Because of these results, ${ }^{99 \mathrm{~m}} \mathrm{Tc}-\mathrm{MIP}-$ 1404 was further examined in an extended time-course tissue distribution study. The results were comparable to the abbreviated tissue distribution study, with rapid clearance from kidney and nontarget tissue. Interestingly, the difference in LNCaP tumor uptake was not statistically significant at any time during the study $(P>0.2)$, indicating that this compound accumulates and is retained preferentially by the tumor. As anticipated from the tissue distribution results, SPECT/CT imaging from 0 to $2 \mathrm{~h}$ depicted a clear 


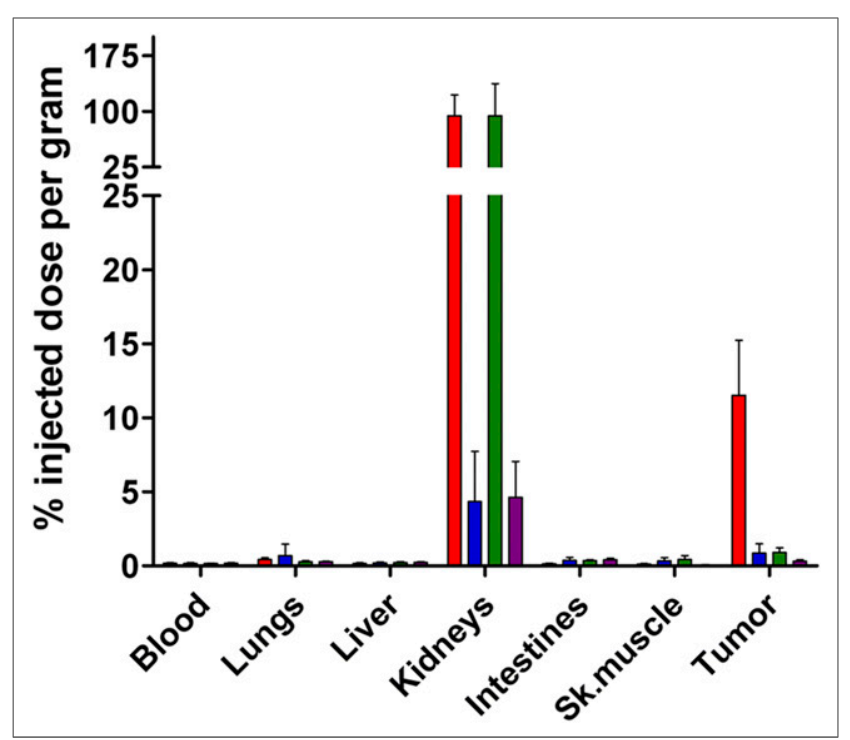

FIGURE 6. Specific binding of $99 \mathrm{mTc}-\mathrm{MIP}-1404$ to PSMA in vivo. 99mTc-MIP-1404, $37 \mathrm{kBq}(2 \mu \mathrm{Ci}) /$ mouse, at specific activity of more than $37 \mathrm{TBq}(1,000 \mathrm{Ci}) / \mathrm{mmol}$ was injected alone (LNCaP tumor, $\square$ PC3 tumor, $\square$ ) or coinjected with $10 \mathrm{mg} / \mathrm{kg}$ dose of PMPA (LNCaP tumor, $\square$; PC3 tumor, $\square$ ) via tail vein. Data are expressed as \%ID/ g. Sk. $=$ skeletal.

abdominal cavity with uptake confined to the kidneys, tumor, and urinary bladder.

Interestingly, whereas kidney uptake of ${ }^{99 \mathrm{~m}} \mathrm{Tc}-\mathrm{MIP}-1404$ competed with PMPA, demonstrating that the uptake is mediated by PSMA, clearance of $99 \mathrm{~m}$ Tc-MIP-1404 from the kidneys was rapid compared with retention in the tumor. The reason for this apparent yet fortuitous discrepancy is under investigation to determine whether it is perhaps the result of differences in PSMA affinity or cellular internalization between these 2 tissues. In our investigational new drug-enabling preclinical studies in rats, no metabolites of ${ }^{99 \mathrm{~m}}$ Tc-MIP-1404 were detected in the urine, ruling out renal metabolism as an explanation for the difference. The combination of prolonged tumor retention and rapid clearance from kidney and nontarget tissues is especially important in imaging prostate cancer, as most locoregional metastases are in the pelvic region and abdominal cavity. These compounds are unlikely to interfere with the physiologic NAALADase activity of glutamatergic neurotransmission, as none of the compounds accumulated in the brain to an appreciable extent, indicating that they do not cross the blood-brain barrier.

Although the tert-butyl ester protected precursor molecules were used for radiolabeling for these preclinical studies, efficient radiolabeling of the fully deprotected precursors has since been accomplished in a rapid and simple kit formulation (17), thereby facilitating the translation of these compounds to the clinic for imaging patients with metastatic prostate cancer. ${ }^{99 \mathrm{~m}} \mathrm{Tc}-\mathrm{MIP}-$ 1404 is currently under clinical investigation in a phase II trial (http://clinicaltrials.gov NCT01667536).

\section{CONCLUSION}

New modalities for the diagnosis, staging, and subsequent monitoring of therapeutic interventions are still an urgent medical need for prostate cancer patients. Small-molecule radiopharmaceuticals such as ${ }^{99 \mathrm{~m}} \mathrm{Tc}-\mathrm{MIP}-1404$, that can potentially be manufactured on demand in a local radiopharmacy, may be capable of detecting both primary prostate cancer and soft-tissue and bone metastases. These agents, designed to specifically track the extent and location of prostate cancer through PSMA expression, could significantly improve patient management and enhance a clinician's ability to select the most beneficial therapeutic intervention.

\section{ACKNOWLEDGMENT}

We thank Prof. Shankar Vallabhajosula for performing the SPECT imaging.

\section{REFERENCES}

1. Kelloff GJ, Sullivan DC, Baker H, et al. Workshop on imaging science development for cancer prevention and preemption. Cancer Biomark. 2007;3: 1-33.

2. Hricak H, Choyke PL, Eberhardt SC, Leibel SA, Scardino PT. Imaging prostate cancer: a multidisciplinary approach. Radiology. 2007;243:28-53.

3. Briganti A, Abdollah F, Nini A, et al. Performance characteristics of computed tomography in detecting lymph node metastases in contemporary patients with prostate cancer treated with extended pelvic lymph node dissection. Eur Urol. 2012;61:1132-1138.

4. Israeli RS, Powell CT, Fair WR, Heston WD. Molecular cloning of a complementary DNA encoding prostate-specific membrane antigen. Cancer Res. 1993;53:227-230.

5. Silver DA, Pellicer I, Fair WR, et al. Prostate-specific membrane antigen expression in normal and malignant human tissues. Clin Cancer Res. 1997;3: 81-85.

6. Horoszewicz JS, Kawinski E, Murphy GP. Monoclonal antibodies to a new antigenic marker in epithelial prostatic cells and serum of prostatic cancer patients. Anticancer Res. 1987;7:927-935.

7. Perner S, Hofer MD, Kim R, et al. Prostate-specific membrane antigen expression as a predictor of prostate cancer progression. Hum Pathol. 2007;38:696-701.

8. Marchal C, Redondo M, Padilla M, et al. Expression of prostate specific membrane antigen (PSMA) in prostatic adenocarcinoma and prostatic intraepithelial neoplasia. Histol Histopathol. 2004;19:715-718.

9. Pinto JT, Suffoletto BP, Bergin TM. Prostate-specific membrane antigen: a novel folate hydrolase in human prostatic carcinoma cells. Clin Cancer Res. 1996;2: 1445-1451.

10. Smith-Jones PM, Vallabahajosula S, Goldsmith SJ, et al. In vitro characterization of radiolabeled monoclonal antibodies specific for the extracellular domain of prostate-specific membrane antigen. Cancer Res. 2000;60:5237-5243.

11. Mesters JR, Henning K, Hilgenfeld R. Human glutamate carboxypeptidase II inhibition: structures of GCPII in complex with two potent inhibitors, quisqualate and 2-PMPA. Acta Crystallogr D Biol Crystallogr. 2007;63:508-513.

12. Barinka C, Byun Y, Dusich CL, et al. Interactions between human glutamate carboxypeptiase II and urea-based inhibitors:structural characterization. J Med Chem. 2008;51:7737-7743.

13. Maresca KP, Hillier SM, Femia FJ, et al. A series of halogenated heterodimeric inhibitors of prostate-specific membrane antigen (PSMA) as radiolabeled probes for targeting prostate cancer. J Med Chem. 2009;52:347-357.

14. Hillier SM, Maresca KP, Femia FJ, et al. Preclinical evaluation of novel glutamate-urea-lysine analogues that target prostate-specific membrane antigen as molecular imaging pharmaceuticals for prostate cancer. Cancer Res. 2009;69: 6932-6940.

15. Barrett JA, LaFrance N, Coleman R, et al. Targeting metastatic prostate cancer [PCa] in patients with ${ }^{123}$ I-MIP1072 and ${ }^{123}$ I-MIP1095 [abstract]. J Nucl Med. 2009;50(suppl):522P.

16. Alberto R, Schibli R, Waibel R, Abram U, Schubiger AP. Basic aqueous chemistry of $\left[\mathrm{M}\left(\mathrm{OH}_{2}\right)_{3}(\mathrm{CO})_{3}\right]^{+}(\mathrm{M}=\mathrm{Re}, \mathrm{Tc})$ directed towards radiopharmaceutical application. Coord Chem Rev. 1999;190-192:901-919.

17. Maresca KM, Wang J, Hillier SH, et al. Development of a simple kit for Tc-99mMIP-1404, a single amino acid chelate (SAAC II) derived small molecule inhibitor of prostate specific membrane antigen (PSMA) for imaging prostate cancer [abstract]. J Nucl Med. 2012;53(suppl 1):159P.

18. Banerjee SR, Foss CA, Castanares M, et al. Synthesis and evaluation of technetium-99m- and rhenium-labeled inhibitors of the prostate-specific membrane antigen (PSMA). J Med Chem. 2008;51:4504-4517.

19. Kularatne SA, Zhou Z, Yang J, Post CB, Low PS. Design, synthesis, and preclinical evaluation of prostate-specific membrane antigen targeted ${ }^{99 \mathrm{~m}}$ Tc-radioimaging agents. Mol Pharm. 2009;6:790-800. 
20. Maresca KP, Hillier SM, Lu G, et al. Small molecule inhibitors of PSMA incorporating technetium-99m for imaging prostate cancer: effects of chelate design on pharmacokinetics. Inorg Chim Acta. 2012;389:168-175.

21. Maresca KP, Marquis JC, Hillier SM, et al. Novel polar single amino acid chelates for technetium- $99 \mathrm{~m}$ tricarbonyl-based radiopharmaceuticals with enhanced renal clearance: application to octreotide. Bioconjug Chem. 2010;21:1032-1042.

22. Lu G, Maresca KP, Hillier SM, et al. Application of novel polar single amino acid chelates to ${ }^{99 \mathrm{~m}} \mathrm{Tc} / \mathrm{Re}$-labeled small molecule prostate specific membrane antigen inhibitors. Bioorg Med Chem Lett. In press.

23. Ascoli M. Internalization and degradation of receptor-bound choriogonadotropin in Leydig tumor cells. J Biol Chem. 1982;257:13306-13311.

24. Public Health Service Policy on Humane Care and Use of Laboratory Animals. National Institutes of Health Web site. http:/grants.nih.gov/grants/OLAW\%20/ references/phspol.htm. Published 2002. Accessed May 15, 2013.

25. Tiffany CW, Lapidus RG, Merion A, Calvin DC, Slusher BS. Characterization of the enzymatic activity of PSM: comparison with brain NAALADase. Prostate. 1999;39:28-35.

26. Schröder FH, Hugosson J, Roobol MJ, et al. Screening and prostate-cancer mortality in a randomized European study. N Engl J Med. 2009;360:1320-1328.

27. Andriole GL, Grubb RL III, Buys SS, et al. Mortality results from a randomized prostate-cancer screening trial. N Engl J Med. 2009;360:1310-1319.

28. Screening for prostate cancer: a review of the evidence for the U.S. Preventive Services Task Force. U.S. Preventive Services Task Force Web site. http://www. uspreventiveservicestaskforce.org/prostatecancerscreening/prostateart.htm. Published October 2011. Accessed May 13, 2013.

29. Delbeke D. Oncological applications of FDG PET imaging. J Nucl Med. 1999;40:1706-1715.

30. Hain SF, Maisey MN. Positron emission tomography in urological tumours. BJU Int. 2003;92:159-164.

31. Troyer JK, Beckett ML, Wright GL. Location of prostate-specific membrane antigen in the LNCaP prostate carcinoma cell line. Prostate. 1997;30:232-242.
32. Troyer JK, Feng Q, Beckett ML, Wright GL. Biochemical characterization and mapping of the 7E11-C5.3 epitope of the prostate-specific membrane antigen. Urol Oncol. 1995;1:29-37.

33. Hövels AM, Heesakkers RA, Adang EM, et al. The diagnostic accuracy of CT and MR in the staging of pelvic lymph nodes in patients with prostate cancer: a meta-analysis. Clin Radiol. 2008;63:387-395.

34. Seabold JE, Ferlic RJ, Marsh JL, Nepola JV. Periarticular bone sites associated with traumatic injury: false positive findings with ${ }^{111} \mathrm{In}$-white blood cells and 99m Tc MDP scintigraphy. Radiology. 1993;186:845-849.

35. Bouchelouche K, Tagawa ST, Goldsmith SJ, Turkbey B, Capala J, Choyke P. PET/CT imaging and radioimmunotherapy of prostate cancer. Semin Nucl Med. 2011;41:29-44.

36. Guilarte TR, McGlothan JL, Foss CA, et al. Glutamate carboxypeptidase II levels in rodent brain using [ ${ }^{125}$ I]DCIT quantitative autoradiography. Neurosci Lett. 2005;387:141-144.

37. Mease RC, Dusich CL, Foss CA, et al. N-[N-[(S)-1,3-dicarboxypropyl]carbamoyl]-4-[ $\left[{ }^{18} \mathrm{~F}\right]$ fluorobenzyl-L-cysteine, $\left[{ }^{18} \mathrm{~F}\right] \mathrm{DCFBC}$ : a new imaging probe for prostate cancer. Clin Cancer Res. 2008;14:3036-3043.

38. Foss CA, Mease RC, Fan H, et al. Radiolabeled small-molecule ligands for prostate-specific membrane antigen: in vivo imaging in experimental models of prostate cancer. Clin Cancer Res. 2005;11:4022-4028.

39. Chen Y, Foss CA, Byun Y, et al. Radiohalogenated prostate-specific membrane antigen (PSMA)-based ureas as imaging agents for prostate cancer. J Med Chem. 2008;51:7933-7943.

40. Liu T, Wu LY, Kazak M, Berkman CE. Cell surface labeling and internalization by a fluorescent inhibitor of prostate-specific membrane antigen. Prostate. 2008; 68:955-964.

41. Bander NH, Milowsky MI, Nanus DM, Kostakoglu L, Vallabhajosula S, Goldsmith SJ. Phase I trial of ${ }^{177}$ lutetium-labeled J591, a monoclonal antibody to prostate-specific membrane antigen, in patients with androgen-independent prostate cancer. J Clin Oncol. 2005;23:4591-4601. 